\title{
Unexpected Postoperative Paraplegia after Thoracotomy in Lung Cancer: Incidental Migration of Oxidized Regenerated Cellulose Used for Hemostasis of Intercostal Space Bleeding
}

\author{
Takanori Ayabe ${ }^{1,2 *}$, Masaki Tomita1, Shigeko Shimizu², Etsuko Yokoyama², Manabu Okumura², \\ Koichiro Itai ${ }^{3}$, Kunihide Nakamura ${ }^{4}$ \\ ${ }^{1}$ Division of Thoracic and Breast Surgery, Department of Surgery, Faculty of Medicine, University of Miyazaki, Miyazaki, Japan \\ ${ }^{2}$ Division of Patient Safety Management, University of Miyazaki Hospital, Miyazaki, Japan \\ ${ }^{3}$ Division of Clinical Ethics, University of Miyazaki Hospital, Miyazaki, Japan \\ ${ }^{4}$ Division of Cardiovascular Surgery, Department of Surgery, Faculty of Medicine, University of Miyazaki, Miyazaki, Japan \\ Email: *tayabe@med.miyazaki-u.ac.jp
}

How to cite this paper: Ayabe, T., Tomita, M., Shimizu, S., Yokoyama, E., Okumura, M., Itai, K. and Nakamura, K. (2017) Unexpected Postoperative Paraplegia after Thoracotomy in Lung Cancer: Incidental Migration of Oxidized Regenerated Cellulose Used for Hemostasis of Intercostal Space Bleeding. Surgical Science, 8, 365-374.

https://doi.org/10.4236/ss.2017.88040

Received: July 17, 2017

Accepted: August 20, 2017

Published: August 23, 2017

Copyright $\odot 2017$ by authors and Scientific Research Publishing Inc. This work is licensed under the Creative Commons Attribution International License (CC BY 4.0).

http://creativecommons.org/licenses/by/4.0/

(c) $\underset{\mathrm{EY}}{(i)}$ Open Access

\begin{abstract}
Background: We experienced a very rare complication, that is, an unexpected postoperative paraplegia due to the incidental migration of oxidized regenerated cellulose used for hemostasis of intercostal space bleeding. Patients and Methods: The objective is to analyze the cause and to take measures against the very rare complication from an empirical analysis and the literature. For a 78-year-old male with suspected lung cancer in the right upper lobe $\left(\mathrm{S}^{1}\right)$, a thoracotomy was performed. For hemostasis of the bleeding from the $5^{\text {th }}$ intercostal thoracotomy space, we used and placed oxidized regenerated cellulose at the continuous oozing bleeding sites. On the $3^{\text {rd }}$ postoperative day, paralysis beneath thoracic vertebrae level 6 was observed. Immediate computed-tomographic (CT) scanning and magnetic resonance imaging (MRI) displayed a $17 \times 9 \times 14 \mathrm{~mm}$ epidural hematoma in the spinal canal at level 5 of the thoracic vertebrae. An emergent laminectomy for the thoracic vertebra was performed to remove the oxidative cellulose and haematoma, and the compression was released. The paraplegia gradually began to recover and maintain a standing position. After 1 year from the event, the patient can walk by himself with a crutch. Results: The causes were that the oxidative cellulose materials were used for the intercostal bleeding at the open thoracotomy. The migration of the oxidative cellulose materials into the epidural space and into thoracic spinal canal through the intervertebral foramen, or gradual penetra-
\end{abstract}


tion of the oxidative cellulose materials into the spinal canal due to respiratory costal movement. As a measurement of prevention, the hemostat materials should be completely removed after finishing of the hemostasis. In the case of a difficult hemostasis, consultation of an orthopedist or neurosurgeon to perform the appropriate hemostasis in good cooperation is required. Conclusion: If postoperative paraplegia is suspected, immediate CT scanning and/or MRI examination would become powerful diagnostic procedures as soon as possible to start an interventional treatment.

\section{Keywords}

Lung Cancer, Incident, Oxidized Regenerated Cellulose, Migration, Thoracotomy, Intercostal Space Bleeding, Paraplegia

\section{Introduction}

Oxidized regenerated cellulose is a commonly used haemostatic agent in various surgical disciplines that gradually increases in volume following saturation with blood [1] [2]. The use of the oxidized regenerated cellulose as a haemostatic agent is common in neurosurgery, orthopaedic surgery and thoracic surgery.

In the chest surgical field, we experienced a very rare complication, that is, an unexpected postoperative paraplegia due to the incidental migration of the oxidized regenerated cellulose used for hemostasis of intercostal space bleeding. Before closing the open thoracotomy wound in lung cancer after confirming intercostal bleeding, we used oxidized regenerated cellulose to arrest the hemostasis. However, as a result, during the early operative phase, postoperative paraplegia occurred. Fortunately, we could obtain the exact location of the spinal canal, and could immediately perform a laminectomy for the thoracic vertebra and remove the expanded oxidative regenerated cellulose with the hematoma compressing the spinal cord from the epidural space. We report a very rare and unexpected incident and the measurement of prevention of recurrence with some references.

\section{Case Report.}

A 78-year-old male with pneumothorax was admitted to our hospital in September, 2011. A $12 \times 10 \mathrm{~mm}$ ground-glass opacity was pointed out in the right upper lobe $\left(\mathrm{S}^{1}\right)$ of a chest computed-tomographic (CT) scan (Figure 1). Primary lung cancer was suspected. A positron emission tomography-CT (PET-CT) showed no abnormal accumulation of the tumor and mediastinal lymph nodes and no distant metastasis. However, lung cancer was suspected ( $\mathrm{rU}, \mathrm{S}^{1}, 12 \times 10$ $\mathrm{mm}, \mathrm{E} 0, \mathrm{D} 0, \mathrm{P} 0, \mathrm{PM} 0, \mathrm{~N} 0$, T1aN0M0, c-stage I). Although the tumor is a central type in the upper lobe, an upper lobectomy was scheduled.

Surgery was performed under general and epidural anesthesia with a doublelumen endobronchial tube. Epidural anesthesia was performed (thoracic verte- 


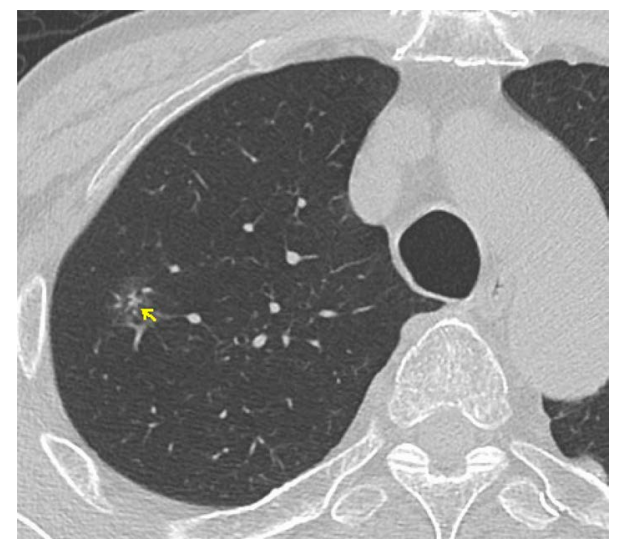

Figure 1. Preoperative computed tomographic scanning of chest. A $12 \times 10 \mathrm{~mm}$ ground-glass opacity was pointed out in the right upper lobe $\left(\mathrm{S}^{1}\right)$ and primary lung cancer was suspected.

brae puncture level: Th6-7; needle type; needle size: 18; depth: $4.5 \mathrm{~cm}$; approach: paramedian method), and no irritative nerve symptom was observed. After establishing single-lung ventilation, the patient was flexed in the lateral decubitus position. After a posterolateral skin incision, a thoracotomy was performed through the $5^{\text {th }}$ intercostal space using the dorsal pedis muscle-sparing technique. During the anatomic resection, we used an endoscopic stapler (Covidien, Tokyo, Japan) to divide the lung parenchyma and incomplete fissures, and excised the bronchus. The pulmonary arteries $\left(\mathrm{A}^{1}, \mathrm{~A}^{2}, \mathrm{~A}^{3}\right)$, veins $\left(\mathrm{V}^{123}\right)$, and upper bronchus $\left(\mathrm{B}^{123}\right)$ were also divided using an endoscopic stapler. The prompt pathological examination of the specimen showed an adenocarcinoma and no metastasis of picking up of the \#10 and \#4 lymph nodes. Air leaks from the suture-lines were closed with sutures and sealed with fibrin glue.

During the closing of the $5^{\text {th }}$ intercostal thoracotomy, bleeding in the vicinity of the intervertebral foramen at the $5^{\text {th }}$ intercostal space was observed. We used electric cautery and an ultrasonic incision and coagulation instrument; however, we could not obtain a sufficient hemostasis-arrest. As a hemostatic agent, we used and placed oxidized regenerated cellulose for the continuous oozing bleeding. During the closure of the $5^{\text {th }}$ intercostal thoracotomy, oxidative regenerated cellulose was used for bleeding from the fossa intercostal space. A 28-F chest tube was placed in the hemithorax, and the wounds were closed. The anesthesia time was 5 hours and 2 minutes, and the operating time was 3 hours and $37 \mathrm{mi}-$ nutes. The blood loss was $460 \mathrm{ml}$.

The postoperative patient was placed in the intensive care unit and there was no complaint of any nerve symptoms. The postoperative analgesic $(0.2 \%$ of ropivacaine, $3 \mathrm{ml} /$ hour) was continued using an epidural anesthesia catheter line for pain management. The patient was allowed to drink water 6 hours after extubation, to eat and walk with assistance by the next morning after surgery and was started on oral analgesia from the first postoperative day.

On the $1^{\text {st }}$ postoperative day of the thoracotomy, an oral painkiller and analgesic drug were medicated for the postoperative thoracotomy wound pain, but 
there were still no nerve symptoms.

On the $2^{\text {nd }}$ postoperative day of the thoracotomy, in the morning, when the patient tried to stand up, he had a feeling of listlessness and he needed assistance to walk to the restroom. The urethral catheter was removed at 10:00 am, but the patient could not walk by himself because of his listlessness and paralysis of the right lower limb. At 14:00, the postoperative continuous epidural analgesic ( $0.2 \%$ of ropivacaine, $3 \mathrm{ml} /$ hour) was stopped and patient transfer was performed using a wheelchair. At 21:00, dysfunction of urination was observed, and the urine drainage catheter was re-inserted.

On the $3^{\text {rd }}$ postoperative day of thoracotomy, in the morning, paralysis of the lower limbs was observed. There was no sensation of pain beneath the xiphoid process of the sternum, no locomotor activity, and urinary retention. After consulting a neurologist, paralysis beneath the thoracic vertebrae level 6 was observed and a spinal cord injury was suspected. CT scanning and magnetic resonance imaging (MRI) of the chest were immediately performed (Figures 2(a)-(c), and Figure 3(a), Figure 3(b)). In the spinal canal at level 5 of the thoracic vertebrae, a $17 \times 9 \times 14 \mathrm{~mm}$ epidural haematoma was found to compress the spinal cord. After consulting an orthopedist, an emergency operation (laminectomy for thoracic vertebra) was performed to remove the foreign body and hematoma. The anesthesia time was 3 hours and 48 minutes, and the operating time was 2 hours and 16 minutes. The blood loss was $180 \mathrm{ml}$. The intraoperative findings showed that the expanded oxidative regenerated cellulose with the hematoma was found in the vertebral canal, which had been used for bleeding from the intercostal space of the thoracotomy, and had compressed the spinal cord from the epidural space. By removal of the oxidative cellulose and hema-

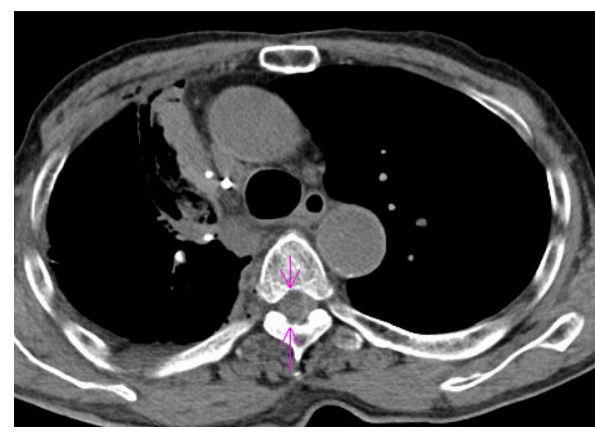

(a)

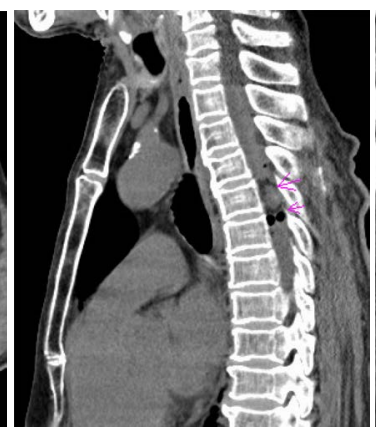

(b)

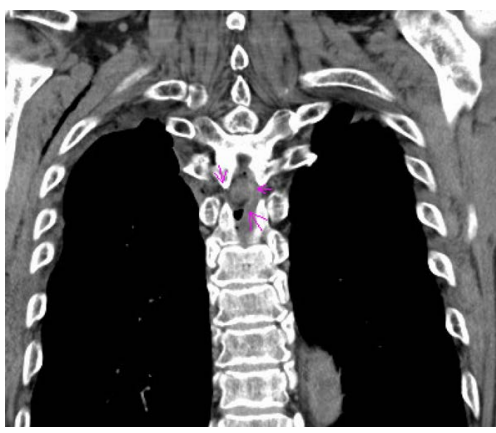

(c)

Figure 2. (a) Postoperative computed tomographic scanning of the chest. In the spinal canal at level 5 of the thoracic vertebrae, a $17 \times 9 \times 14 \mathrm{~mm}$ low density mass, which was suspected to be a foreign body and/or epidural haematoma (pink arrows). The spinal cord was suspected to be compressed and shifted to the left side; (b) Postoperative computed tomographic scanning of thoracic vertebrae and spinal canal (sagittal plane). In the spinal canal at level 5 of the thoracic vertebrae, a foreign body mass or epidural haematoma were observed in the spinal canal. There were air bubbles (pink arrows); (c) Postoperative computed tomographic scanning of thoracic vertebrae and spinal cord (coronal plane). The epidural space at level 5 of the thoracic vertebrae was connected to the thoracic spinal canal through the intervertebral foramen, where a foreign body mass, epidural haematoma (pink arrows) and air were observed, which compressed the left side from the right side and the spinal cord shifted to the left side. 


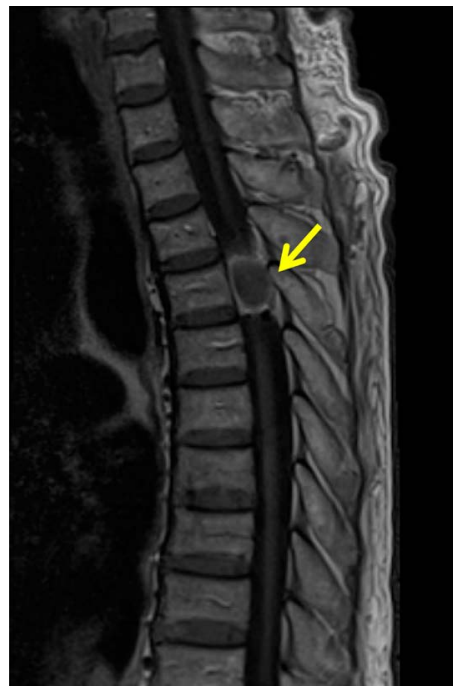

(a)

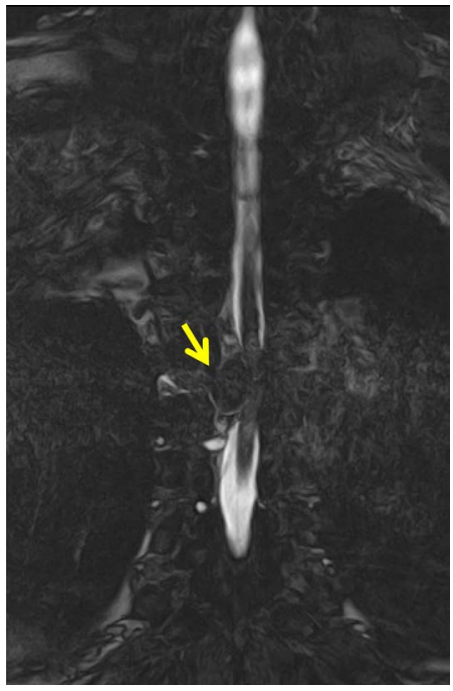

(b)

Figure 3. (a) Postoperative magnetic resonance imaging of thoracic vertebrae and spinal canal (sagittal plane). In the spinal canal at level 5 of the thoracic vertebrae, a foreign body and/or epidural haematoma as a low intensity area (yellow arrows) was observed in the cerebrospinal fluid as a high intensity area in the spinal canal; (b) Postoperative magnetic resonance imaging of thoracic vertebrae and spinal cord (coronal plane). In the spinal canal at level 5 of the thoracic vertebrae, a low intensity area, which was suspected to be a foreign body and/or epidural haematoma (yellow arrows) was found to compress the spinal cord to the left side from the right side.

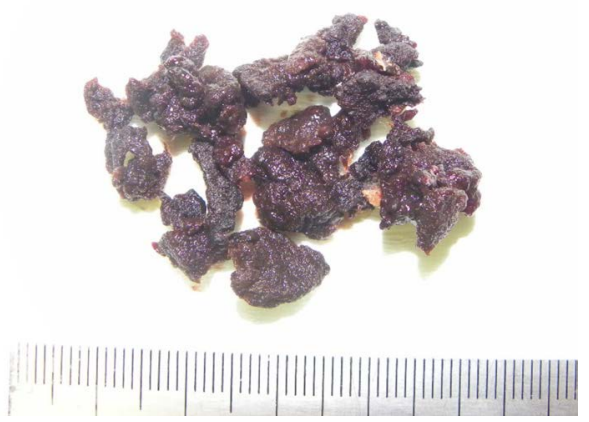

Figure 4. A photo of the intraoperative specimen. The expanded oxidative regenerated cellulose with hematoma were removed from the spinal canal.

toma (Figure 4, Figure 5(a), Figure 5(b)), the compression was released.

On the $6^{\text {th }}$ postoperative day of the laminectomy, the patient could bend the right knee of his lower limb to a mild degree. The bed rest level was expanded to the wheelchair transfer from sitting down on the bed-side. Upon letting the patient go to a standing position, he could not stand upright due to his left lower limb.

On the $11^{\text {th }}$ postoperative day of the laminectomy, the urine drainage catheter was removed.

Although the sense of defecation was recovering, however, there is no sense of urination, and a neurogenic bladder was diagnosed, thus withdrawing urine was 


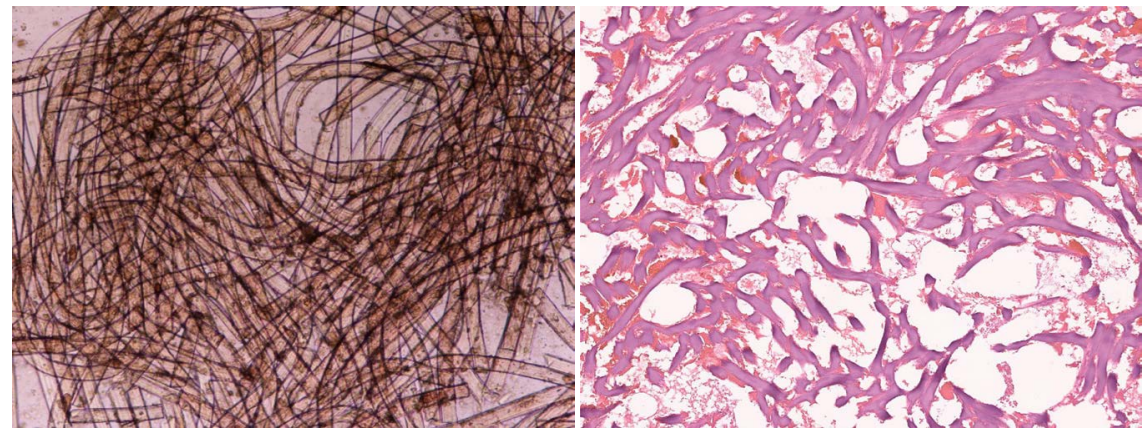

(a)

(b)

Figure 5. (a) Photomicrograph. (No staining). The fibers of the cellulose materials were clearly observed; (b) Microscopic findings of fibers of oxidative cellulose (Hematoxylin and eosin stain). Structures of fibers of cellulose and blood materials were observed.

assisted 4 to 5 times a day. After the implementation of rehabilitation for paraplegia at an early stage, the paraplegia gradually began to recover and he was able to maintain a standing position. Although the patient had atelectasis of the right middle lobe and pneumonia of the right lower lobe, intravenous drip infusion of antibiotics, postural drainage therapy, and biphasic intermittent positive airway pressure were performed. The atelectasis and pneumonia improved.

On the $46^{\text {th }}$ postoperative day of the laminectomy, the patient was moved to another hospital to receive aggressive rehabilitation.

At the postoperative one year later, the patient can walk by himself with a crutch.

Informed consent was obtained from the patient to report this incident case.

\section{Discussion}

Paraplegia following nonspinal surgery is a rare complication that has been reported after surgery of the thoracic or abdominal aorta [3] [4] [5], pulmonary surgery [6], and epidural catheterization [7]. In contrast, paraplegia after thoracotomy is an extremely uncommon complication, with an estimated incidence of $0.08 \%[1]$.

As a diagnostic examination of the neurological level of paraplegia, high resolution CT-scanning could differentiate between the surgical sponge and a haematoma. In addition, MRI is also the best investigative tool in such cases. MRI delineates the location of a lesion and the degree of cord compression. Hyperacute haematomas appear hypointense or slightly hyperintense in the T1weighted images and have a mixed signal intensity in the T2-weighted images. Acute haematomas are also isointense in the T1-weighted images, but more hypointense on the T2-weighted images; chronic haematomas are hyperintense in all sequences [8]. In the present case, CT-scanning and MRI could display the difference in a haematoma and foreign body and also the degree of migration of oxidative cellulose materials, the degree of compression, and the level of the spinal cord (Figure 2 and Figure 3 ).

The oxidative cellulose was developed in 1959, more than 30 years ago, and 
has been generally and widely used for various surgical procedures to arrest haemostasis. If the oxidative cellulose materials were placed at the spot of a serious effusion in the body, almost $100 \%$ of it should be absorbed within two weeks, the characteristics of which contained blood and expanded and compressed the bleeding origin, and which compressed the bleeding and arrested the hemostasis by compression.

Regarding the precautions for use in the attached document of SURGICEL as an "Absorbable Hemostat" (Johnson \& Johnson, Tokyo, Japan) [9], there is a description, that is, "in the next case, it is to remove the used oxidative cellulose materials after achievement of hemostat", that is, especially, "in the case of use of hemostat assist for lobectomy, a part of which migrated to the circumference of the spinal cord" [9] and that occurred to bring a compression-related neuropathy. Based on the precaution for use in the attached document of SURGICEL ${ }^{\circ}$ [9], three cases of paraplegia due to an open thoracotomy for lung cancer were reported.

Table 1 shows a summary of the reported cases of post-thoracotomy paraplegia due to oxidized regenerated cellulose, which had been reported by S Dogan

Table 1. A summary of reported cases of post-thoracotomy paraplegia due to oxidized regenerated cellulose, which had been reported by S Dogan et al. (2005), and our present case was added in the list. Our case was the oldest and the postoperative paraplegia improved. Regarding the outcome after post-thoracotomy paraplegia $(n=15)$, there were observed improvement $(n=6,6 / 15$, $40 \%)$ and no improvement $(60 \%, \mathrm{n}=9,9 / 15,60 \%)$.

\begin{tabular}{|c|c|c|c|c|c|c|c|c|}
\hline $\begin{array}{l}\text { Case } \\
\text { No. }\end{array}$ & Authors & year & $\begin{array}{c}\text { Patient } \\
\text { age } \\
\text { (years) }\end{array}$ & site & Operation & $\begin{array}{c}\text { Neurologic } \\
\text { level }\end{array}$ & Outcome & $\begin{array}{l}\text { Reference } \\
\text { No. }\end{array}$ \\
\hline 1 & Perez-Guerra, F. et al. & 1984 & 59 & $\mathrm{~L}$ & Pneumonectomy & Th5 & Paraplegia; no improvement & 11 \\
\hline 2 & Tashiro, C. et al. & 1987 & 56 & $\mathrm{R}$ & Upper lobectomy & Th5 & Brown-Squard Syndrome improvement & 12 \\
\hline 3 & Short H.D. et al. & 1990 & 49 & $\mathrm{R}$ & Upper lobectomy & Th5-6 & Left leg improved, right monoplegia & 9 \\
\hline 4 & Short H.D. et al. & 1990 & 59 & $\mathrm{R}$ & Lower lobectomy & Th5-6 & Paraplegia & 9 \\
\hline 5 & Short H.D. et al. & 1990 & 72 & $\mathrm{R}$ & $\begin{array}{l}\text { Upper and middle } \\
\text { lobectomy }\end{array}$ & Th5-6 & Paraplegia & 9 \\
\hline 6 & Wada, E. et al. & 1993 & 37 & $\mathrm{R}$ & Upper lobectomy & Th5 & improved & 13 \\
\hline 7 & Wada, E. et al. & 1993 & 69 & $\mathrm{R}$ & Upper lobectomy & Th5 & improved & 13 \\
\hline 8 & Iwabuchi, S. et al. & 1997 & 46 & $\mathrm{R}$ & Lower lobectomy & Th5 & Paraparesis & 14 \\
\hline 9 & Løvstad, R.Z. et al. & 2002 & 56 & $\mathrm{~L}$ & Lower lobectomy & Th8 & Paraplegia & 15 \\
\hline 10 & Brodbelt, A.R. et al. & 2002 & 15 & $\mathrm{R}$ & $\begin{array}{l}\text { Ventriculoseptal defect and } \\
\text { pulmonary artery stenosis }\end{array}$ & Th5-6 & Paraparesis & 2 \\
\hline 11 & Brodbelt, A.R. et al. & 2002 & 37 & $\mathrm{~L}$ & Lower lobectomy & Th5 & died & 2 \\
\hline 12 & Brodbelt, A.R. et al. & 2002 & 50 & $\mathrm{R}$ & $\begin{array}{l}\text { Thoracic crush injury } \\
\text { (haemorrhage cintrol) }\end{array}$ & - & Right leg monoparesis & 2 \\
\hline 13 & Biglioli, P. et al. & 2002 & 38 & $\mathrm{~L}$ & Thoraci aortic aneurysm & Th6 & Paraplegia & 3 \\
\hline 14 & Dogan, S. et al. & 2005 & 22 & $\mathrm{~L}$ & $\begin{array}{c}\text { Thoracotomy (another } \\
\text { institution) }\end{array}$ & Th6 & Right leg partially improved, left monoplegia & 10 \\
\hline 15 & Ayabe, T. et al. & 2017 & 78 & $\mathrm{R}$ & Upper lobectomy & Th5 & Paraplegia, improved & Present case \\
\hline
\end{tabular}


et al. [10], and our present case was added to the list. We evaluated 15 cases [2] [3] [9]-[15], which were reported between 1984 and 2017. The patient age ranged between 15 to 78 years-old, in which our case was the most elderly. The right operative site was observed in 10 cases and the left side was in 5 cases. The variations in the operative procedures were pneumonectomy $(n=1)$, bilobectomy $(n=1)$, lobectomy $(n=9)$, cardiovascular surgery $(n=2)$, traumatic surgery $(\mathrm{n}=1)$, and thoracotomy (unknown, $\mathrm{n}=1$ ). The neurological injury level was Th5 $(\mathrm{n}=7)$, Th6 $(\mathrm{n}=2)$, Th5-6 $(\mathrm{n}=4)$, Th8 $(\mathrm{n}=1)$, and unknown $(\mathrm{n}=1)$. Regarding the outcome after the post-thoracotomy paraplegia, there was observed an improvement $(\mathrm{n}=6,6 / 15,40 \%)$ and no improvement $(60 \%, \mathrm{n}=9,9 / 15$, $60 \%)$.

In the present incidental case of postoperative paraplegia, we performed a minimally invasive thoracotomy without resecting of the ribs, however, the bleeding and oozing points at the intercostal space and circumference of the intervertebral foramen were difficult to do a certain hemostasis because of the significantly narrow space, thus, a suture and a ligation could not be performed, and the oxidative cellulose material was used to fill the intercostal space and circumference of the intervertebral foramen, and as a result, such a situation caused the oxidative cellulose materials to expand with the haematoma, which was sandwiched between the narrowing intercostal spaces when the thorax was closed. The migration of the oxidative cellulose materials into the epidural space and into the thoracic spinal canal through the intervertebral foramen or gradually sticking out of the oxidative cellulose materials into the spinal canal due to the respiratory costal movement. It might take 2 or 3 days for compression of the spinal cord by the expanded oxidative cellulose materials to happen and occurrence of the postoperative paraplegia.

Regarding the precautions for use in the attached document of SURGICEL, "after the precise confirmation of the hemostat, removal of the used oxidative cellulose materials should be required" is described. In the present case, we used cotton-like oxidative cellulose materials; however, the complete removal of the gelated oxidative cellulose materials was difficult. The use of cotton-type oxidative cellulose materials must be avoided. When required for use, the sheet-type should be used because it is easy to remove.

We investigated the cause of this rare incident regarding the postoperative paraplegia. This contribution should be seeking the truth from the facts and we also developed preventive measures. As a prevent recurrence, the major points are 1) to reduce bleeding at the thoracotomy, 2) do not hesitate to resect ribs at the thoracotomy to widen the operative field, 3) to try a total hemostasis in case of intercostal bleeding, 4) in case of inevitable use of oxidative cellulose materials for the thoracotomy, total removal of the oxidative cellulose materials after achievement of hemostasis, 5) do not use cotton-type oxidative cellulose materials or use a sheet-type and its subsequent remove, and 6) in the case of uncontrollable bleeding near the intervertebral foramen, perform a hemostasis after consulting and cooperating with a neurosurgeon and/or orthopedist. This re- 
search mainly contributed to the fact that using oxidative cellulose materials for the bleeding had better not be performed. Based on the seeking truth from facts in the present case study, the complete removal should be recommended.

As a limitation of this case study, young thoracic surgeons might have not known of such a very rare complication of postoperative paraplegia due to the migration of oxidative cellulose materials. Because, as a recent minimally invasive surgery, a video-assisted thoracic surgery has been developed and has been actively performed for chest surgery and there is no need to use oxidative cellulose materials. On the other hand, an open invasive and large thoracotomy has been occasionally performed for advanced lung cancer and similar cases. When using oxidative cellulose materials as a hemostat in surgery, we have to inform of such a rare incident and the necessity of its removal to colleagues and young surgeons.

\section{Conclusion}

As a measurement of preventing the recurrence of postoperative paraplegia from the hemostasis of intercostal bleeding, do not proceed with a thoracotomy line in the vicinity of the intervertebral foramen and not allow bleeding from the intercostal space; do not hesitate to perform a thoracotomy with resecting ribs. In the case of intercostal bleeding, try the appropriate hemostasis, and in the case of using a hemostat, completely remove the hemostat materials after finishing the hemostasis. Do not use a flock-type oxidative cellulose for the hemostasis of the intercostal space. However, a sheet-type should be recommended for use with easy removal as soon as possible. In case of a difficult hemostasis, after consulting an orthopedist or neurosurgeon, the appropriate hemostasis should be needed with good cooperation.

\section{References}

[1] Attar, S., Hankins, J.R., Turney, S.Z., Krasna, M.J. and McLaughlin, J.S. (1995) Paraplegia after Thoracotomy: Report of Five Cases and Review of the Literature. Annals Thoracic Surgery, 59, 1410-1416.

http://www.annalsthoracicsurgery.org/article/0003-4975(95)00196-R/pdf https://doi.org/10.1016/0003-4975(95)00196-R

[2] Brodbelt, A.R., Miles, J.B., Foy, P.M. and Broome, J.C. (2002) Intraspinal Oxidised Cellulose (Surgicel) Causing Delayed Paraplegia after Thoracotomy-A Report of Three Cases. Annals of the Royal College of Surgeons of England, 84, 97-99. https://www.ncbi.nlm.nih.gov/pmc/articles/PMC2503802/pdf/annrcse01636-0031.p df

[3] Biglioli, P., Roberto, M., Cannata, A., Parolari, A. and Spirito, R. (2002) Paraplegia after Iatrogenic Extrinsic Spinal Cord Compression after Descending Thoracic Aorta Repair: Case Report and Literature Review. The Journal of Thoracic and Cardiovascular Surgery, 124, 407-410. https://doi.org/10.1067/mtc.2002.122138

[4] Cowley, R.A., Turney, S.Z., Hankins, J.R., Rodriguez, A., Attar, S. and Shankar, B.S. (1990) Rupture of Thoracic Aorta Caused by Blunt Trauma. A Fifteen-Year Experience. The Journal of Thoracic and Cardiovascular Surgery, 100, 652-601.

[5] Szilagyi, D.E., Hageman, J.H., Smith, R.F. and Elliott, J.P. (1978) Spinal Cord Dam- 
age in Surgery of the Abdominal Aorta. Surgery, 83, 38-56.

[6] Batellier, J., Wihlm, J.M., Morand, G. and Witz, J.P. (1989) Paraplegia Caused by Extradural Spinal Hematoma after Radical Pulmonary Lobectomy in Cancer. Annales De Chirurgie, 43, 210-214.

[7] Wulf, H. (1996) Epidural Anaesthesia and Spinal Haematoma. Canadian Journal of Anaesthesia, 43, 1260-1271. https://doi.org/10.1007/BF03013437

[8] Felber, S., Langmaier, J., Judmaier, W., Dessl, A., Ortler, M., Birbamer, G. and Piepgras, U. (1994) Magnetic Resonance Tomography in Epidural and Subdural Spinal Hematoma. Radiologe, 34, 656-661.

[9] Short, H.D. (1990) Paraplegia Associated with the Use of Oxidized Cellulose in Posterolateral Thoracotomy Incisions. Annals Thoracic Surgery, 50, 288-290. http://www.annalsthoracicsurgery.org/article/0003-4975(90)90751-Q/pdf https://doi.org/10.1016/0003-4975(90)90751-Q

[10] Dogan, S., Kocaeli, H. and Doygun, M. (2005) Oxidised Regenerated Cellulose as a Cause Of Paraplegia after Thoracotomy: Case Report and Review of the Literature. Spinal Cord, 43, 445-447. https://doi.org/10.1038/sj.sc.3101632

[11] Perez-Guerra, F. and Holland, J.M. (1984) Epidural Hematoma as a Cause of Postpneumonectomy Paraplegia. Annals Thoracic Surgery, 39, 282. https://doi.org/10.1016/S0003-4975(10)62599-4

[12] Tashiro, C., Iwasaki, M., Nakahara, K. and Yoshiya, I. (1987) Postoperative Paraplegia Associated with Epidural Narcotic Administration. Canadian Journal of Anaesthesia, 34, 190-192. https://doi.org/10.1007/BF03015345

[13] Wada, E., Yonenobu, K., Ebara, S., Kuwahara, O. and Ono, K. (1993) Epidural Migration of Hemostatic Agents as a Cause of Postthoracotomy Paraplegia. Report of Two Cases. Journal of Neurosurgery, 78, 658-660. https://doi.org/10.3171/jns.1993.78.4.0658

[14] Iwabuchi, S., Koike, K., Okabe, T., Tago, S. and Murakami, T. (1997) Iatrogenic Paraplegia Caused by Surgicel Used for Hemostasis during a Thoracotomy: Report of a Case. Surgery Today, 27, 969-970. https://doi.org/10.1007/BF02388149

[15] Løvstad, R.Z., Steen, P.A. and Forsman, M. (1999) Paraplegia after Thoracotomy-Not Caused by the Epidural Catheter. Acta Anaesthesiologica Scandinavica, 43, 230-232. https://doi.org/10.1034/j.1399-6576.1999.430220.x

\section{Submit or recommend next manuscript to SCIRP and we will provide best service for you:}

Accepting pre-submission inquiries through Email, Facebook, LinkedIn, Twitter, etc. A wide selection of journals (inclusive of 9 subjects, more than 200 journals)

Providing 24-hour high-quality service

User-friendly online submission system

Fair and swift peer-review system

Efficient typesetting and proofreading procedure

Display of the result of downloads and visits, as well as the number of cited articles

Maximum dissemination of your research work

Submit your manuscript at: http://papersubmission.scirp.org/

Orcontactss@scirp.org 